\title{
A Study on Supply Chain Coordination Mechanism in the Environment of Consumers and Retailers Co-creation
}

\author{
Yingjin LU \\ School of Management and Economics, \\ University of Electronic Science and Technology of China \\ Chengdu, China \\ e-mail: luyingjin@uestc.edu.dn
}

\author{
Jing WANG \\ School of Management and Economics, \\ University of Electronic Science and Technology of China \\ Chengdu, China \\ e-mail:wj392154308@163.com
}

\begin{abstract}
With the development of the Internet, consumers have been more and more involved in the process of co-creating value. However, the research on the supply chain involves little. This paper introduces the efforts of consumers and retailers, based on Stackelberg game Model, the supply chain profit model is built, respectively, the retail price, sales volume, effort and the total profit of the supply chain are analyzed for the co-creation efforts of consumers and retailers under centralized and decentralized situation. The results show that centralized decision-making is the most effective coordination mechanism for supply chain in the context of consumer and retailer co-creation.
\end{abstract}

Keywords-co-creation; game theory; supply chain coordination; decentralized decision-making; centralized decision-making

\section{INTRODUCTION}

With the rapid development of the Internet economy as well as science and technology, the business and consumer status as well as the way to realize the value has the major changes, consumers began to become user-creators. However, Enterprise managers in the observation of the ability of consumers to participate in the development of products and services, gradually, enterprise began to attach the need for consumers to co-create. Taobao, apple and other companies to create a successful model to prove the value of this point.

However, the theory of value co-creation is far behind the practice, especially, about the supply chain co-create research involves very little. Wang Wenbin, Da Qingli (2007) [1], under the premise of considering the interests of consumers and the whole society, profit distribution of the secondary supply chain under three kinds of reverse supply chain, which is dominated by manufacturers, has been studied. Wang Li, Li Han (2011) [2] considered innovation of a supply chain with one supplier, one manufacturer and one retailer, respectively, some results are analyzed, including total profit, sales of product, retail price of supply chain, individual innovation investment and individual profit in decentralized and concentrated situation. The total profit of supply chain in concentrated situation by two ways, which are three-member distribution and two-step distribution of profit, is distributed. The result shows that a reasonable allocation method can improve overall performance of the supply chain system. Niladri B. Syam, Amit Pazgal (2013) [3] described the creation of externalities in which production is co-create by the firm and its customers, and the firm will increase the effort it devotes to co-creation as the number of potential co-creating customers' increases. The firm sets prices, the customers decide whether to buy or not. In addition, to solve for the optimal prices sang effort level, we use the concept of a subgame-perfect equilibrium and backwards induction. At present, about the supply chain innovation research takes into account the influence of innovation profits and sales volume among supply chain, and does not consider the influence of consumers' participation in the whole profit and sales volume and sales price of the supply chain. Moreover, at present, in the market, consumers have the right to choose the preferred option in the field of commodity circulation, and retailers as the end of the circulation of goods can fully grasp the market information. Therefore, the priority of the introduction of consumer and retailer efforts level, then the profits were compared with two cases (Only consider the supply chain retailers to separate efforts; customers and retailer effort together) of the supply chain under decentralized and centralized situation.

\section{BUILD A MODEL OF CO-CREATION AND SOLVE}

Considering a three-level supply chain consisting of a single supplier, a manufacturer, and a retailer, as shown in Figure 1 (left part of the dotted line). In this paper, it is assumed that the retailer is in the dominant position and the consumer is in the subordinate position. Within the supply chain, the retailer is the weak enterprise and the supplier is the core enterprise [4-6]. 


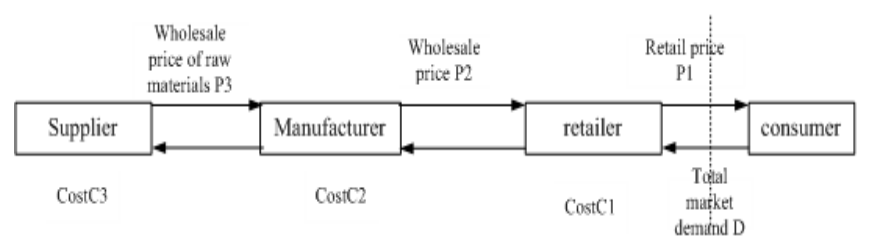

Figure 1. Three-level supply chain structure

Assuming that the supply chain member' information is fully shared, the unit price of the raw material supplied by the supplier is $P_{3}$, the manufacturer provides the retailer with the wholesale price is $P_{2}, P_{1}$ is the price charged to a consumer for the product. The selling cost of the retailer is $C_{1}$, the manufacturing cost of the manufacturer is $C_{2}$, the manufacturing cost of the parts of the supplier is $C_{3}$. The paper does not consider the stock cost and the stock cost and so on. $C_{1}, C_{2}, C_{3}$ were constant, and $d=C_{1}+C_{2}+C_{3}$.

This article will be for product innovation and product design contribution is called "effort". In the supply chain, let the production "effort" of the retailer be $e_{f}$ and that of a consumer be $e_{u}$. Each consumer benefit from the combined total effort. Specifically, we define the total effort $\widetilde{e_{u}}$ as $\widetilde{e_{u}}=e_{u}+\delta_{f} e_{f}$, where $\delta_{f} \leq 1$ means the level of effort substitutability between the retailer and the consumer. The consumer's benefit is thus a function $b(\cdot)$ of the above total effort. Assuming that the effort cost is the squared relationship of the effort level, that is $c(e)=c e^{2}$, the effort cost is zero when the effort is zero, that is $c(0)=0$. At this point, the total consumer surplus is given by $C S_{u}=b\left(\widetilde{e_{u}}\right)-$ $c e_{u}^{2}-P_{1}+\varepsilon$, where $\varepsilon$ is a zero mean random variable representing uncertainty the consumer has about the fit of the products to her needs and we assume that $\varepsilon$ is distributed uniformly on $[-\theta, \theta]$, and then the probability that a consumer purchases is thus $\operatorname{Pr}\left[\varepsilon \geq P-b\left(\widetilde{e_{u}}\right)\right]=\frac{\theta+b\left(\widetilde{e_{u}}\right)-P}{2 \theta}$. When $D$ is the potential demand for the market, the retailer's order quantity is $Q=D * P r$. We assume the retailer's order quantity is the manufacturer's production capacity, also is the supplier's supply.

\section{A. Without Co-creation}

\section{1) Decentralized decision-making}

Decentralized decision-making refers to the suppliers, manufacturers and retailers are standing in the perspective of maximizing themselves revenue to order the number of how much. In the hypothetical three-level supply chain, when the retailer pays extra effort alone and the consumer's effort cost is zero, that is $e_{u}=0, b\left(\widetilde{e_{u 1}}\right)=\delta_{f} e_{f}$ and $P r_{1}=$
$\frac{\theta+b\left(\widetilde{e_{11}}\right)-P_{11}}{2 \theta}, Q=D * P r_{1}$.

The expected profit of the retailer is $\pi_{l 1}=\left(P_{11}-P_{21}-\right.$ $\left.C_{1}\right) * \operatorname{Pr}_{1} * D-c e_{f 1}^{2}$

Manufacturer profit function is $\pi_{z 1}=\left(P_{21}-P_{31}-C_{2}\right) *$ $P r_{1} * D$

Supplier profit function is $\pi_{z 1}=\left(P_{31}-C_{3}\right) * P r_{1} * D$

The expected total profit of the supply chain is $\Pi_{1}=$ $\pi_{l 1}+\pi_{z 1}+\pi_{s 1}=\left(P_{11}-C_{1}-C_{2}-C_{3}\right) * P r_{1} * D-c e_{f 1}^{2}$.

To solve for the optimal prices, effort level and total profit, we use the concept of a subgame-perfect equilibrium and backwards induction. So Start at the last stage.

Stage 3: Since the retailer is the weakest of the supply chain, the retailer reacts after the manufacturer has made a decision on the supplier. Retailers will treat $P_{21}, P_{31}, e_{f 1}$ as known, choose $P_{11}$ to maximize their own profits by $\frac{\partial \pi_{l 1}}{\partial P_{11}}=0$ and the result is $P_{11}=\frac{\theta+b\left(\widetilde{e_{11}}\right)+\left(P_{21}+C_{1}\right)}{2}$.

Stage 2: In the case of complete information, the manufacturer knows that the retailer's decision thinking $P_{21}$ will be adjust and the manufacturer chooses to maximize his / her own profit by $\frac{\partial \pi_{z 1}}{\partial P_{21}}=0$ and the result is $P_{21}=$ $\frac{\theta+b\left(\widetilde{e_{u 1}}\right)+\left(P_{31}+C_{2}-C_{1}\right)}{2}$.

Stage 1: In the case of complete information, the supplier knows that the manufacturer's decision-making ideas $P_{31}$ will be adjusted, the supplier chooses $P_{31}$ to maximize its own profit by $\frac{\partial \pi_{s 1}}{\partial P_{31}}=0$, and the result is $P_{31}=\frac{\theta+b\left(\widetilde{e_{u 1}}\right)+\left(C_{3}-C_{2}-C_{1}\right)}{2}$. Then putting $P_{31}$ into $P_{21}, P_{11}, \Pi_{1}$ and getting $P_{11}=\frac{7\left(\theta+b\left(\widetilde{e_{u 1}}\right)\right)+d}{2}, P_{21}=$ $\frac{3\left(\theta+b\left(\widetilde{e_{u 1}}\right)\right)-\left(3 C_{1}-C_{3}-C_{2}\right)}{2}, \Pi_{1}=\frac{7\left[\left(\theta+b\left(\widetilde{e_{u 1}}\right)\right)-d\right]^{2}}{128} D-c e_{f 1}^{2}$.

And then the total profit's FOC gives $\frac{\partial \Pi_{1}}{\partial e_{f 1}}=0$, this gives the optimal effort of retailer as $e_{f 1}=\frac{7 \delta_{f} D(\theta-d)}{128 c \theta-7 D \delta_{f}{ }^{2}}$, next putting it into the profit function, and getting the optimal profit of the supply chain without co-creation is $\Pi_{1}=$ $\frac{7 c D(\theta-d)^{2}}{128 c \theta-7 D \delta_{f}^{2}} \quad, \quad P r_{1}=\frac{8 c(\theta-d)}{128 c \theta-7 D \delta_{f}^{2}} \quad, \quad b\left(\widetilde{e_{u 1}}\right)=\delta_{f} e_{f 1}=$ $\frac{7 \delta_{f}^{2} D(\theta-d)}{128 c \theta-7 D \delta_{f}^{2}}$, and $P_{11}=\frac{16 c \theta(7 \theta+d)-7 \delta_{f}^{2} D d}{128 c \theta-7 D \delta_{f}{ }^{2}}$. Clearly for the effort and the profit to be positive, we need $128 c \theta-$ $7 D \delta_{f}^{2}>0$ and $\theta-d>0$.

\section{2) Centralized decision-making}

Centralized decision-making means that suppliers, manufacturers and retailers are in the supply chain to 
maximize the total revenue perspective to determine the order size. Therefore, the expected total profit of the supply chain is $\Pi_{1}{ }^{\prime}=\left(P_{11}{ }^{\prime}-C_{1}-C_{2}-C_{3}\right) * P r_{1}{ }^{\prime} * D-c e_{f 1}^{\prime}{ }^{2}$.

By profit maximization method, and getting $\Pi_{1}{ }^{\prime}=\frac{c D(\theta-d)^{2}}{8 c \theta-D \delta_{f}{ }^{2}} \quad, \quad b\left(\widetilde{e_{u 1}}\right)^{\prime}=\delta_{f} e_{f 1}^{\prime}=\frac{\delta_{f}{ }^{2} D(\theta-d)}{8 c \theta-D \delta_{f}{ }^{2}} \quad$, $e_{f 1}^{\prime}=\frac{\delta_{f} D(\theta-d)}{8 c \theta-D \delta_{f}^{2}}, \quad P r_{1}^{\prime}=\frac{2 c(\theta-d)}{8 c \theta-D \delta_{f}^{2}}, \quad P_{11}{ }^{\prime}=\frac{4 c \theta(\theta+d)-\delta_{f}^{2} D d}{8 c \theta-D \delta_{f}^{2}}$. Clearly, for the effort and the profit to be positive, we need8c $\theta-D \delta_{f}^{2}>0$.

\section{B. Co-creation of Consumers and Retailers}

When consumers and retailers to co-create, the consumer's benefit is $\left(\widetilde{e_{u}}\right)=e_{u}+\delta_{f} e_{f}$, at this time, the need to calculate the expected profit of consumers. However, if the final product does not meet the expectations of consumers, consumers may choose not to buy, therefore, the consumer's expected profit is

$E\left[C S_{u}\right] E\left[C S_{u}\right.$ if u buys $\mid$ u buys $] \operatorname{Pr}[u$ buys $]$ * $E\left[C S_{u}\right.$ if u doesn't buys|u doesn't buys ]* $\operatorname{Pr}[u$ doesn't buys $]-c(e)$.

In addition, as already noted, the probability of purchase in the future is independent of the cost of effort. Thus, the consumer's expected profit function is

$$
\begin{aligned}
& \Pi_{g 2}=\left[b\left(\widetilde{e_{u 2}}\right)-P_{12}+\varepsilon \mid \varepsilon \geq P-b\left(\widetilde{e_{u 2}}\right)\right] * \\
& P r_{2}\left[\varepsilon \geq P-b\left(\widetilde{e_{u 2}}\right)\right] * D-c e_{u 2}^{2}=\frac{\left(\theta+b\left(\widetilde{e_{u 2}}\right)-P_{12}\right)^{2}}{4 \theta} * D- \\
& c e_{u 2}^{2}
\end{aligned}
$$

\section{1) Decentralized decision-making}

Considering the case of decentralized decision-making with co-creation, the probability of purchase is $P r_{2}=$ $\frac{\theta+b\left(\widetilde{u_{2}}\right)-P_{12}}{2 \theta}$, so the supply chain retailers, manufacturers and suppliers profit function is expressed as

The expected profit of the retailer is $\pi_{l 2}=\left(P_{12}-P_{22}-\right.$ $\left.C_{1}\right) * P r_{2} * D-c e_{f 2}^{2}$

Manufacturer profit function is $\pi_{z 2}=\left(P_{22}-P_{32}-C_{2}\right) *$ $P r_{2} * D$

Supplier profit function is $\pi_{z 2}=\left(P_{32}-C_{3}\right) * P r_{2} * D$

The expected total profit of the supply chain is $\Pi_{2}=$ $\pi_{l 2}+\pi_{z 2}+\pi_{s 2}=\left(P_{12}-C_{1}-C_{2}-C_{3}\right) * P r_{2} * D-c e_{f 2}^{2}$.

According to the Stackelberg game model, the solution is
$P_{12}=\frac{7\left(\theta+b\left(\widetilde{u_{u}}\right)\right)+d}{8}$.

The total profit function of the supply chain is: $\Pi_{2}=$ $\frac{7\left[\left(\theta+b\left(\widetilde{e_{u}}\right)\right)-d\right]^{2}}{128 \theta} D-c e_{f 2}^{2}$

At this point, putting the market retail price $P_{12}$ into the consumer's expected profit function, and getting the consumer profit is $\Pi_{g 2}=\frac{7\left[\left(\theta+b\left(\widetilde{e_{u}}\right)\right)-d\right]^{2}}{256 \theta} D-c e_{u}^{2}$.

The consumer's FOC $\frac{\partial \Pi_{g 2}}{\partial e_{u 2}}=0$ and the supply chain's FOC $\frac{\partial \Pi_{2}}{\partial e_{f 2}}=0$, the solutions for the consumer's and the supply chain's efforts are $e_{u 2}=\frac{D(\theta-d)}{256 c \theta-14 D \delta_{f}{ }^{2}-D}$ and $e_{f 2}=\frac{14 D \delta_{f}(\theta-d)}{256 c \theta-14 D \delta_{f}{ }^{2}-D}$.

Thus $\quad b\left(\widetilde{e_{u 2}}\right)=\delta_{f} e_{f 2}+e_{u 2}=\frac{\left(14 D \delta_{f}^{2}+D\right)(\theta-d)}{256 c \theta-14 D \delta_{f}^{2}-D}$, $P r_{2}=\frac{16 c(\theta-d)}{256 c \theta-14 D \delta_{f}^{2}-D} \quad, \quad P_{12}=\frac{32 c \theta(7 \theta+d)-14 \delta_{f}^{2} D d-D d}{256 c \theta-14 D \delta_{f}^{2}-D}$, $\Pi_{2}=\frac{14 c D(\theta-d)^{2}\left(256 \theta-14 D \delta_{f}^{2}\right)}{\left(256 c \theta-14 D \delta_{f}^{2}-D\right)^{2}}$.

Clearly for the effort and the profit to be positive, we need $256 c \theta-14 D \delta_{f}^{2}-D>0$ and $\theta-d>0$.

\section{2) Centralized decision-making}

The total profit function of the supply chain in Centralized decision-making with co-creation is $\Pi_{2}{ }^{\prime}=$ $\left(P_{12}{ }^{\prime}-C_{1}-C_{2}-C_{3}\right) * P r_{2}{ }^{\prime} * D-c e_{f 2}^{\prime}{ }^{2}$.

The Consumer profit function is $\Pi_{g 2}{ }^{\prime}=\frac{\left(\theta+b\left(\widetilde{e_{u 2}}\right)^{\prime}-P_{12}\right)^{2}}{4 \theta} *$ $D-c e_{u 1}^{\prime 2}$.

In the same way, to get $e_{f 2}^{\prime}=\frac{2 D \delta_{f}(\theta-d)}{16 c \theta-2 D \delta_{f}{ }^{2}-D}, e_{u 2}^{\prime}=$ $\frac{D(\theta-d)}{16 c \theta-2 D \delta_{f}^{2}-D} \quad, \quad b\left(\widetilde{e_{u}}\right)_{2}^{\prime}=\frac{\left(D+2 \delta_{f}^{2} D\right)(\theta-d)}{16 c \theta-2 D \delta_{f}{ }^{2}-D} \quad, \quad P r_{2}{ }^{\prime}=$ $\frac{4 c(\theta-d)}{16 c \theta-2 D \delta_{f}{ }^{2}-D} \quad, \quad \Pi_{2}{ }^{\prime}=\frac{4 c D(\theta-d)^{2}\left(8 \theta-D \delta_{f}{ }^{2}\right)}{\left(16 c \theta-2 D \delta_{f}{ }^{2}-D\right)^{2}} \quad$, $P_{12}{ }^{\prime}=\frac{8 c \theta(\theta+d)-2 \delta_{f}^{2} D d-D d}{16 c \theta-2 D \delta_{f}{ }^{2}-D}$. Clearly for the effort and the profit to be positive, we need $16 c \theta-2 D \delta_{f}{ }^{2}-D>0$ and $\theta-d>0$. 


\section{RESULTS AND COMPARISON}

Statistics for the two cases are listed table 1.

TABLE I. COMParison of Three CASES OF CONSUMER PARTICIPATION IN THE SUPPly Chain

\begin{tabular}{|c|c|c|}
\hline variable & Without co-creation (1) & Co-creation of consumers and retailers (2) \\
\hline \multicolumn{3}{|c|}{ Decentralized decision-making } \\
\hline$\Pi$ & $\Pi_{1}=\frac{7 \mathrm{cD}(\theta-\mathrm{d})^{2}}{128 \mathrm{c} \theta-7 \mathrm{D} \delta_{f}{ }^{2}}$ & $\Pi_{2}=\frac{14 c D(\theta-d)^{2}\left(256 \theta-14 D \delta_{f}^{2}\right)}{\left(256 c \theta-14 D \delta_{f}^{2}-D\right)^{2}}$ \\
\hline $\operatorname{Pr}$ & $P r_{1}=\frac{8 c(\theta-d)}{128 c \theta-7 D \delta_{f}^{2}}$ & $P r_{2}=\frac{16 c(\theta-d)}{256 c \theta-14 D \delta_{f}^{2}-D}$ \\
\hline$e_{u}$ & - & $e_{u 2}=\frac{D(\theta-d)}{256 c \theta-14 D \delta_{f}^{2}-D}$ \\
\hline$e_{f}$ & $e_{f 1}=\frac{7 \delta_{f} D(\theta-d)}{128 c \theta-7 D \delta_{f}^{2}}$ & $e_{f 2}=\frac{14 D \delta_{f}(\theta-d)}{256 c \theta-14 D \delta_{f}^{2}-D}$ \\
\hline$b\left(\widetilde{e_{u}}\right)$ & $b\left(\widetilde{e_{u 1}}\right)=\frac{7 \delta_{f}^{2} D(\theta-d)}{128 c \theta-7 D \delta_{f}^{2}}$ & $b\left(\widetilde{e_{u 2}}\right)=\frac{\left(14 D \delta_{f}^{2}+D\right)(\theta-d)}{256 c \theta-14 D \delta_{f}^{2}-D}$ \\
\hline$P_{1}$ & $P_{11}=\frac{16 c \theta(7 \theta+d)-7 \delta_{f}^{2} D d}{128 c \theta-7 D \delta_{f}^{2}}$ & $P_{12}=\frac{32 c \theta(7 \theta+d)-14 \delta_{f}^{2} D d-D d}{256 c \theta-14 D \delta_{f}^{2}-D}$ \\
\hline
\end{tabular}

\begin{tabular}{ccc}
\hline & Centralized decision-making \\
\hline$\Pi^{\prime}$ & $\Pi_{1}{ }^{\prime}=\frac{c D(\theta-d)^{2}}{8 c \theta-D \delta_{f}{ }^{2}}$ & $\Pi_{2}{ }^{\prime}=\frac{4 c D(\theta-d)^{2}\left(8 \theta-D \delta_{f}{ }^{2}\right)}{\left(16 c \theta-2 D \delta_{f}{ }^{2}-D\right)^{2}}$ \\
\hline$P r^{\prime}$ & $P_{1}{ }^{\prime}=\frac{2 c(\theta-d)}{8 c \theta-D \delta_{f}{ }^{2}}$ & $\operatorname{Pr}_{2}{ }^{\prime}=\frac{4 c(\theta-d)}{16 c \theta-2 D \delta_{f}{ }^{2}-D}$ \\
\hline$e_{u^{\prime}}$ & - & $e_{u 2}^{\prime}=\frac{D(\theta-d)}{16 c \theta-2 D \delta_{f}{ }^{2}-D}$ \\
\hline$e_{f}{ }^{\prime}$ & $e_{f 1}^{\prime}=\frac{\delta_{f} D(\theta-d)}{8 c \theta-D \delta_{f}{ }^{2}}$ & $e_{f 2}^{\prime}=\frac{2 D \delta_{f}(\theta-d)}{16 c \theta-2 D \delta_{f}{ }^{2}-D}$ \\
\hline$\left.\widetilde{e}_{u}\right)^{\prime}$ & $b\left(\widetilde{e_{u 1}}\right)^{\prime}=\frac{\delta_{f}{ }^{2} D(\theta-d)}{8 c \theta-D \delta_{f}{ }^{2}}$ & $b\left(\widetilde{e_{u 2}}\right)=\frac{\left(14 D \delta_{f}{ }^{2}+D\right)(\theta-d)}{256 c \theta-14 D \delta_{f}{ }^{2}-D}$ \\
\hline$P_{1}{ }^{\prime}$ & $P_{11}{ }^{\prime}=\frac{4 c \theta(\theta+d)-\delta_{f}{ }^{2} D d}{8 c \theta-D \delta_{f}{ }^{2}}$ & $P_{12}{ }^{\prime}=\frac{8 c \theta(\theta+d)-2 \delta_{f}{ }^{2} D d-D d}{16 c \theta-2 D \delta_{f}{ }^{2}-D}$
\end{tabular}

Among them: $128 c \theta-7 D \delta_{f}^{2}>0,8 c \theta-D \delta_{f}^{2}>$ $0,16 c \theta-2 D \delta_{f}^{2}-D>0,256 c \theta-14 D \delta_{f}^{2}-D>0, \theta-$ $d>0$.

Through the analysis of Table 1 available conclusions are:
- In two cases, comparison of Total Profit, Sales, and Retail prices of Supply Chains in decentralized and centralized decision-making except consumers.

(1) $\Pi_{1}<\Pi_{1}{ }^{\prime}, P r_{1}<P r_{1}{ }^{\prime}$, when $D<\frac{32 c \theta}{7 \delta_{f}}$, $P_{11}>P_{11}{ }^{\prime}$, when $D>\frac{32 c \theta}{7 \delta_{f}}, P_{11}<P_{11}{ }^{\prime}$. 
(2) $\Pi_{2}<\Pi_{2}^{\prime}, \operatorname{Pr}_{2}<\operatorname{Pr}_{2}^{\prime}$, when $\mathrm{D}<\frac{192 \mathrm{c} \theta}{27+42 \delta_{f}{ }^{2}}$, $P_{12}>P_{12}{ }^{\prime}$, when $\mathrm{D}>\frac{192 \mathrm{c} \theta}{27+42 \delta_{f}^{2}}, P_{12}<P_{12}{ }^{\prime}$.

Conclusion 1: In the case of centralized decision-making, the total profit of the three-level supply chain is higher than the decentralized decision-making, and the sales volume is larger than the decentralized decision.

- In the case of centralized decision-making and decentralized decision-making, comparison of the efforts of consumers and retailers

(1) $e_{f 1}<e_{f 1}^{\prime}, b\left(\widetilde{e_{u}}\right)_{1}<b\left(\widetilde{e_{u}}\right)_{1}^{\prime}$;

(2) $e_{f 2}<e_{f 2}^{\prime}, e_{u 2}<e_{u 2}^{\prime}, \quad b\left(\widetilde{e_{u}}\right)_{2}<b\left(\widetilde{e_{u}}\right)_{2}^{\prime}$.

Conclusion 2: Whether it is a consumer or retailer, the level of effort in centralized decision-making is greater than that of decentralized decision-making, which can increase the retailer's sales and improve the customer's satisfaction.

- The comparison of three kinds of situations in centralized decision-making

$\Pi_{1}{ }^{\prime}<\Pi_{2}{ }^{\prime}, \quad e_{f 2}^{\prime}>e_{f 1}^{\prime}, \quad b\left(\widetilde{e_{u}}\right)_{2}^{\prime}>b\left(\widetilde{e_{u}}\right)_{1}^{\prime}, P r_{1}{ }^{\prime}<P r_{2}{ }^{\prime}$, $P_{11}{ }^{\prime}<P_{12}{ }^{\prime}$.

Conclusion 3: Co-creation can improve the total profit of the supply chain, which is the level of effort and order quantity from the point of view of the total profit of the supply chain.

\section{CONCLUSION}

In this paper, we consider a three-level supply chain and a consumer as research object. Based on the premise of retailers and consumers with co-creation, this paper analyzes and compares the total profits of supply chain and the level of consumers and retailers' effort in the decentralized decision-making and centralized decision-making. In order to better understand the advantages of consumer participation in the co-creation, we also need a more in-depth discussion.

\section{ACKNOWLEDGMENT}

This research was financially supported by The Ministry of education of Humanities and Social Science project (13JDGC002).

\section{REFERENCES}

[1] Wenbin Wang, Qingli Da. Distribution of profit in reverse supply chain with consumer surplus consideration [J]. Journal of Southeast University (Natural Science Edition), 2007, 37 (4): 726-730.

[2] Li Wang, Han Li. Research on profit distribution of three-level supply chain based on Innovation of members [J]. Journal of Jiangsu University of Science and Technology (Natural Science Edition), 2011, 25 (3): 276-281.

[3] Syam N B, Pazgal A. Co-Creation with Production Externalities [J]. Marketing Science, 2013, 32(5):805-820

[4] Zhou. Research on the cooperative profit allocation methods in downstream supply chain [D]. Jiangsu University of Science and Technology, 2008

[5] Yan Zou, Yuke Chen, Jingrong Dong. Vertical R \& D alliance strategy of the midstream enterprise in a three-level supply chain [J]. Journal of engineering management, 2011, 25 (1): 216-220.

[6] Xuemei ZHANG, Jinzhong LENG. Optimization Strategy between Manufacturer and Service Providers under Presale Service Affecting Product Demand [J]. Systems Engineering, 2016, 34(1): 102-107. 